Destillationskolben aufgesetzten Dephlegmator austretenden Dämpfe in einen zweiten Kolben geleitet werden und zwar bis auf den Boden desselben. Die sich dort verdichtende Flüssigkeit dient zum Waschen der durch sie hindurch geleiteten Dämpfe. Dieselben passiren nun einen auf diesen Waschkolben aufgesetzten zweiten Dephlegmator, gelangen in einen zweiten Kolben von eben beschriebener Art und in gleicher Weise schliesslich noch in einen dritten, vierten und in manchen Fällen fünften. Die aus dem letzten austretenden Dämpfe werden erst als Destillat aufgefangen. Hat man eine Fraction gesammelt und beginnt der Siedepunkt zu steigen, so entfernt man die Flamme unter dem eigentlichen Destillationsgefäss und lässt den Inhalt der sämmtlichen Dephlegmationskolben wieder zurücksaugen. Man beginnt dann in gleicher Weise wieder zu destilliren wie vorstehend beschrieben.

F. Rasińsi*) hat Mittheilungen über die fractionirte Destillation des Erdöls von Baku mit Hülfe von Wasserdampf gemacht, bei der er im übrigen die eben beschriebene Anordnung des Apparates beibehielt und nur statt das Destillationsgefäss von aussen zu erhitzen in dasselbe Wasserdampf einleitete. Die Resultate dieser nenen Fractionirungsmethode scheinen recht befriedigende zu sein.

Auch M. J. Lazarus**) hat sich mit Vortheil des eingeleiteten Wasserdampfes zum Erhitzen beim Fractioniren bedient und zwar namentlich in solchen Fällen, wo leicht zersetzbare, mit Wasser nicht mischbare Flüssigkeiten zu destilliren waren, da unter diesen Umständen der Siedepunkt vieler Substanzen, die sonst erst über $100^{\circ}$ sieden, unter dem des Wassers liegt und deshalb einer Zersetzung derselben leichter vorgebeugt werden kann.

Um beim fractionirten Destilliren unter vermindertem Druck ein gleichmässiges Vacuum zu erzeugen, schaltet L. Godef r o y***) zwischen die Luftpumpe und das Auffangegefäss einen Regulator ein, auf den ich hier nur hinweisen kann. Ebenso muss ich auch bezüglich der Einrichtung zum Wechseln der Vorlage auf das Original verweisen.

Zur genauen Bestimmung des Schmelzpunktes empfiehlt $C$. Gräbef) die Angaben des neben dem Schmelzpunktsröhrchen befind-

*) Journal für praktische Chemie [N. F.] 29, 39 und 31, 428.

**) Ber. d. deutsch. chem. Gesellsch. za Berlin 18, 577 .

***) Annales de chimie et de physique [6. Série] 1, 138 .

†) Chem. Centralblatt [3. F.] 16, 833 . 
lichen Thermometers durch ein zweites Thermometer zu controliren, dessen Quecksilber bis zum Beobachtungspunkt fast ganz in das Heizbad eingetaucht ist. $\mathrm{Zu}$ diesem $\mathrm{Zweck}$ hat man drei Vergleichsthermometer nöthig, bei denen sich der eine Fixpunkt, der Siedepunkt des Wassers, resp. Naphtalins oder Benzophenons dicht über der Thermometerkugel befindet.

\section{Zum Aufschliessen der Siiicate mittelst der Alkalicarbonate} macht Fr. Stolba*) folgende Mittheilungen, deren Zweck es ist, darauf aufmerksam zu machen, dass sich mit Hülfe eines einfachen Kunstgriffes die weitere Behandlung der mittelst Alkalicarbonaten aufgeschlossenen Silicate, wie die Entleerung des Platintiegels und rasche Lösung des aufgeschlossenen Silicates ungemein erleichtern lässt.

Das Silicat wird wie gewöhnlich mit etwa dem vierfachen Gewicht kohlensauren Natrons innig gemischt und in bekannter Art behandelt, bis es bei Glühhitze keine weitere Einwirkung erleidet.

Alsdann überschichtet man die glühende Masse mit ihrem halben bis gleichen Volum vorher abgeknisterten Chlornatriums und erhitzt bei bedecktem Platintiegel, bis sie ruhig fliesst. Sobald der Inhalt des Platintiegels eine dünnflüssige Masse darstellt, wird derselbe auf eine passende Unterlage entleert, und, wenn hinreichend erkaltet, mit Wasser gekocht. Die Masse zergeht, bis auf die vorhandenen im Wasser unlöslichen Stoffe, ungemein rasch und wird hierauf in bekannter Art mit Salzsäure behandelt, zur Trockne abgedampft u. s. w.

In manchen Fällen wird das Aufschliessen beim nachherigen Zusatz von Chlornatrium noch vervollständigt, namentlich wenn Stoffe vorhanden sind, welche ein Zusammenfliessen verhindern, weil in der nunmehr dünnflüssigen Masse eine Einwirkung auf etwa unaufgeschlossene Theile des Silicats erleichtert wird.

Die Vortheile des angegebenen Kunstgriffes sind demmach folgende:

1. Wird an den ersten Arbeiten nichts geändert.

2. Wird durch den Zusatz von Chlornatrium die Masse stets dünnflüssig and ist demnach zum Ausgiessen geeignet.

3. Wird sie leichter löslich, da sämmtliche Theile von dem leichtlöslichen Chlornatrium durchdrungen und eingehüllt sind, wodurch die Einwirkung des Wassers und der Säure erleichtert wird.

*) Sitzungsberichte der königl. böhm. Gesellschaft der Wissenschaften 1885; vom Verfasser als Separatabdruck eingesandt. 